\title{
Anther Evolution: Pollen Presentation Strategies When Pollinators Differ
}

\author{
Maria Clara Castellanos, ${ }^{1, \star}$ Paul Wilson, ${ }^{2, \dagger}$ Sarah J. Keller, ${ }^{3, \ddagger}$ Andrea D. Wolfe, ${ }^{4, \S}$ and James D. Thomson ${ }^{1, \|}$
}

1. Department of Zoology, University of Toronto, Toronto, Ontario M5S 3G5, Canada; and Rocky Mountain Biological Laboratory, Crested Butte, Colorado 81224;

2. Department of Biology, California State University, Northridge, California 91330;

3. Division of Biological Sciences, University of Montana, Missoula, Montana 59812;

4. Department of Evolution, Ecology, and Organismal Biology,

Ohio State University, Columbus, Ohio 43210

Submitted October 24, 2004; Accepted September 28, 2005;

Electronically published December 12, 2005

Online enhancements: appendixes.

Aвstract: Male-male competition in plants is thought to exert selection on flower morphology and on the temporal presentation of pollen. Theory suggests that a plant's pollen dosing strategy should evolve to match the abundance and pollen transfer efficiency of its pollinators. Simultaneous pollen presentation should be favored when pollinators are infrequent or efficient at delivering the pollen they remove, whereas gradual dosing should optimize delivery by frequent and wasteful pollinators. Among Penstemon and Keckiella species, anthers vary in ways that affect pollen release, and the morphology of dried anthers reliably indicates how they dispense pollen. In these genera, hummingbird pollination has evolved repeatedly from hymenopteran pollination. Pollen production does not change with evolutionary shifts between pollinators. We show that after we control for phylogeny, hymenopteran-adapted species present their pollen more gradually than hummingbird-adapted relatives. In a species pair that seemed to defy the pattern, the rhythm of anther maturation produced an equivalent dosing effect. These results accord with previous findings that hummingbirds can be more efficient than bees at delivering pollen.

\footnotetext{
* Corresponding author. Present address: Estación Biológica de Doñana, Avenida Maria Luisa s/n, 41013 Seville, Spain; e-mail: mcastel@ebd.csic.es.

† E-mail: paul.wilson@csun.edu.

* E-mail: sarah.keller@umontana.edu.

§ E-mail: wolfe.205@osu.edu.

"| E-mail: jthomson@zoo.utoronto.ca.
}

Am. Nat. 2006. Vol. 167, pp. 288-296. (c) 2006 by The University of Chicago. 0003-0147/2006/16702-40698\$15.00. All rights reserved.
Keywords: floral evolution, pollen dispensing, sexual selection, malemale competition, pollen-ovule ratios, Penstemon.

In angiosperms, individuals potentially compete to donate pollen to receptive stigmas. Because of this, sexual selection, defined as selection caused by differences in mating success (Arnold 1994), can shape floral characters (Bell 1985; Queller 1997). For many plants, such competition involves pollinators. This ought to engender certain evolutionary dynamics affecting floral traits (Willson 1979) comparable with the dynamics surrounding the evolution of male genitalia in animals that copulate (Hosken and Stockley 2004) or the evolution of elaborate male plumage in birds (Badyaev and Hill 2003). Male-male competition can favor the evolution of floral attractiveness characters, such as showy petals and rapidly replenishing nectar, and traits that affect the physical interaction between pollinator and flower (Wilson et al. 1994).

Traits that determine the timing of pollen pickup by pollinators can also be targets of sexual selection (Lloyd and Yates 1982). Many plants present pollen in doses, either by packaging (staggering the opening of anthers, flowers, or inflorescences) or by dispensing (restricting the amount removed from a package by a single visit). Adaptive explanations for pollen presentation patterns have centered on modeling the efficiency of transfer of pollen grains. Collectively, these models make up "pollen presentation theory" (Harder and Thomson 1989; Harder and Wilson 1994, 1998; LeBuhn and Holsinger 1998; Thomson 2003) and suggest that, in principle, plants can increase male fitness by adjusting the schedule of pollen presentation to the quality and quantity of pollinators. Analogous proposals have been offered to explain the metering of sperm in certain fishes (Warner et al. 1995; Wedell et al. 2002).

Consider, for example, how bees and birds differ in their efficiencies of pollen transfer. Focus on pollen transfer after single visits. If an animal dislodges $R$ grains from a donor flower and subsequently deposits $D_{\text {sum }}$ of them on the stigmas of all recipient flowers, we define pollen transfer efficiency as $D_{\text {sum }} / R$. All else being equal, we expect that 
pollen transfer efficiency will be higher for birds than for bees for three reasons. First, bees are more likely to groom pollen grains off the stigma-contacting surfaces of their bodies. Bees groom very frequently during foraging bouts, combing their bodies with specially modified groups of leg hairs that effectively sweep pollen into collection organs (scopae or corbiculae), where it has little or no chance of being deposited on a stigma (Rademaker et al. 1997). Hummingbirds, in contrast, tend to preen only between bouts, and they lack specialized grooming devices. In consequence, a pollen grain on the forehead of a hummingbird will probably stay there for a large number of flower visits. A grain on the back of a bee is likely to be taken out of circulation much sooner. Second, this proposition is supported by studies of pollen carryover by bees and birds visiting species of Penstemon (Castellanos et al. 2003). The carryover curves for bees decline more steeply, indicating a more rapid depletion of the active pool of grains on a bee. Also, $D_{\text {sum }} / R$ is greater for birds visiting a bird-adapted Penstemon species than for either birds or bees visiting a bee-adapted species. Third, bumblebees, at least, and probably all bees, tend to groom more thoroughly after they have been dusted with a heavy load of pollen (Thomson and Thomson 1989; Harder 1990a, 1990b). Therefore, a plant that presents twice as much pollen to a bee visitor is not likely to get twice as many of those grains delivered to stigmas. Instead, grooming triggered by excessive pollen acquisition imposes diminishing returns on the numbers of grains delivered. At least for bees, it is probable that plant male fitness gains decelerate as plants make more pollen available at one time (Janzen 1977; Lloyd 1984; Yund 1998). For hummingbirds, the comparatively negligible role of grooming during foraging suggests that diminishing returns are less pronounced.

We therefore predicted that flowers adapted to pollination by hummingbirds should present their pollen more freely (with less dosing) than closely related species that are adapted for pollination by bees (Thomson et al. 2000). Optimal pollen presentation tactics for successful pollen delivery are theoretically affected by several other processes not considered here, particularly visitation rates and the extent of pollen removal from anthers. Nevertheless, we here test this simple prediction in the clade "penstemons" (the tribe Cheloneae, including Penstemon and Keckiella). Among penstemons, hummingbird pollination has arisen more than a dozen times in lineages primitively adapted to bees and wasps (Wilson et al. 2006). Penstemons are morphologically well suited to dispense pollen via narrowly dehiscing anthers, and they can practice packaging by controlling the timing of anther or flower openings.

In addition to anther dehiscence, the amount of pollen produced might also evolve with pollinator type. Pollen production might be expected to be lower in plants pol- linated by hummingbirds if anther dehiscence were held constant. And within a pollination type, those species that release pollen more gradually might produce less pollen than those that open their anthers widely because the latter would be subjected to greater pollen wastage. Pollen production has also been related to ovule number. If a species has a small number of ovules per flower, then one expects fewer pollen grains. This topic was originally explored by Cruden $(1972,1976)$ in terms of the efficiency of the pollen transfer system, but he did not distinguish male from female reproductive success. Charnov (1982) redirected attention to local mate competition via male function, whereby pollen production would evolve in excess of what is needed to set seed because plants would be competing to sire seed.

Detailed pollen presentation schedules have been described for a few bee-pollinated species (Percival 1955; Thomson and Barrett 1981; Harder 1990b; Thomson and Thomson 1992; Robertson and Lloyd 1993; LeBuhn and Anderson 1994; Bell and Cresswell 1998; Larson and Barrett 1999; Sargent 2003). We here compare bee- and birdadapted penstemons. First, we characterize anther dehiscence schedules using a novel method for quantifying pollen presentation. Second, we show that bird-adapted species tend to have less restrictive anther dehiscence than bee-pollinated species after we account for phylogeny. Third, in a species pair that violates this trend, we show that the bee-adapted species achieves more gradual dosing through packaging. Finally, we show that our results are not confounded by differences in pollen production.

\section{Methods}

Penstemon anthers vary in the morphology of dehiscence, and this variation was important to the delineation of subgenera in the traditional taxonomy. The ancestral condition (found in Keckiella and most of the 186 species of the traditional subgenus Penstemon) is to have locules that dehisce from end to end. At full dehiscence, anthers may be shaped like a canoe or be fully explanate. In traditional subgenus Habroanthus (46 spp.), anthers dehisce from the distal end toward a connective but not across it. Some species open wide; others open narrowly. Subgenus Saccanthera (26 spp.) has anthers that dehisce across the connective, leaving sacs on either side. Anthers of Dasanthera (9 spp.) open across the connective, as in the ancestral condition, but the edges of the locules are densely wooly. At the level of the traditional subgenera, anther morphology is unrelated to pollinator type. Both bee and bird pollination occur in many sections (Lodewick and Lodewick 1999), and the numerous shifts to bird pollination are strongly supported by phylogenies based on the nuclear internal transcribed spacer (ITS) region and on the chro- 
mosomal trn region (app. A in the online edition of the American Naturalist; Wilson et al. 2005; A. Wolfe, unpublished data). The most parsimonious scenario implies 25 originations of hummingbird pollination; 14 of them are strongly supported as separate. In other words, bird pollination appeared independently in groups with contrasting anther morphology.

\section{Detailed Pollen Dispensing Schedules}

We developed a standard technique to quantify pollen dispensing by anthers. Every $0.5 \mathrm{~h}$, we brushed an anther with a small square of velvet fabric. This "velvet method" allowed us to dislodge grains using a hairy surface similar to that of a bee's body or the feathers of a hummingbird's head, yet allowed the grains to be counted on a microscope slide after further preparation (details in app. B in the online edition of the American Naturalist).

We used the velvet method on single anthers in flowers from which the other three anthers had been removed before the start of dehiscence. Sampling lasted for the period of normal dehiscence, between 5 and $16 \mathrm{~h}$. The first brushing was done shortly before dehiscence, when the anther had started to shrink as it dried. We sampled three to seven flowers of each of 13 species; when possible, we sampled on different days and from different individuals. Six species are hummingbird pollinated and seven are bee pollinated (table 1), allowing us to designate four blocks of close relatives with contrasting pollinators.

Statistical analysis focused on the cumulative number of grains as a function of sampling time (e.g., fig. B1). We described these curves with two parameters. First, we used the half-life of the pollen pool, defined as the time after initial anther dehiscence at which half of the pollen grains had been released by the anther. A longer half-life indicates more protracted dispensing. Second, we calculated the proportion of the total number of grains in the anther that were released onto the first 10 velvet samples $(4.5 \mathrm{~h})$ of each run. The total number of grains was the sum of the grains collected during sampling plus those remaining in the anther. By using the first 10 samples, we avoided the problem that some flowers were sampled for longer than others. The two parameters are not independent but emphasize different aspects of the dispensing curves.

\section{Morphological Variation in Anther Dehiscence}

We scored the extent of anther dehiscence in dried stamens of 69 species. The characteristic extent of dehiscence is preserved indefinitely in dried specimens. Fully dehisced, flawless anthers were mounted on aluminum stubs. Under a dissecting scope, we sorted the species blindly from narrowest to widest opening. This yielded "dehiscence ranks" from 1 to 69 . In the group of species in the traditional subgenus Saccanthera, anthers dehisce by a slit near the connective with sacs of pollen on either side (block D, app. A). These were judged to be the most narrowly dehiscent (dehiscence ranks 1-9), with all other species dehiscing wider (10-69). This judgment is debatable in a few cases, but the morphology of the anthers of this group is so different from other penstemons that comparable rankings are uncertain. A few other species were also dif-

Table 1: Values of pollen dispensing variables in 13 species of Penstemon and Keckiella studied in the greenhouse

\begin{tabular}{|c|c|c|c|c|c|}
\hline Species & Pollinator & Mean half-life & $\begin{array}{l}\text { Mean proportion of } \\
\text { grains in first } 4.5 \mathrm{~h}\end{array}$ & Dehiscence rank & $n$ \\
\hline P. laetus ${ }^{1}$ & Bee & 15.88 & .02 & 2 & 8 \\
\hline P. rostriflorus ${ }^{1}$ & Hummingbird & 14.30 & .05 & 8 & 7 \\
\hline P. barbatus ${ }^{2}$ & Hummingbird & 6.25 & .08 & 13 & 4 \\
\hline P. strictus ${ }^{2}$ & Bee & 16.40 & .06 & 16 & 5 \\
\hline P. alpinus & Bee & 15.33 & .10 & 17 & 3 \\
\hline P. neomexicanus & Bee & 11.20 & .41 & 33 & 5 \\
\hline P. glabrescens & Bee & 10.20 & .32 & 34 & 5 \\
\hline P. gentryi ${ }^{3}$ & Bee & 4.20 & .53 & 44 & 6 \\
\hline K. breviflora ${ }^{4}$ & Bee & 5.00 & .70 & 52 & 2 \\
\hline P. newberryi & Bird and bee & 6.50 & .53 & 58 & 4 \\
\hline K. ternata ${ }^{4}$ & Hummingbird & 4.60 & .89 & 65 & 5 \\
\hline P. kunthii ${ }^{3}$ & Hummingbird & 2.20 & .93 & 66 & 6 \\
\hline P. centranthifolius & Hummingbird & 4.40 & .77 & 67 & 5 \\
\hline
\end{tabular}

Note: Half-life of the pollen pool in an anther and the proportion of grains released in the first $4.5 \mathrm{~h}$ of sampling were measured from the cumulative curves of pollen release of one anther. Species are sorted in the table according to how wide open the anthers look after complete dehiscence, when ranked among 69 species (dehiscence rank) from the most restrictive (low ranks) to very wide (high ranks). Species names with the same superscript form part of a closely related pair with contrasting pollinators; $n=$ flowers sampled with the velvet pollen-removal method. 
ficult to rank because of their special morphology. For instance, the edges of Penstemon neomexicanus locules fold back very wide, but the anthers have deep furrows that might retain pollen. Small differences in ranks, for example, 62 versus 63 versus 64, do not indicate meaningful distinctions. As the difference in ranks becomes greater, confidence increases.

In addition to presenting the ranks of all 69 species, we compared close relatives, some of which are hummingbird pollinated and others hymenopteran pollinated. Pollinators were assigned using our previous field surveys of floral visitors (Wilson et al. 2004). We reexamined the small sets of close relatives and judged whether species that are more hummingbird pollinated have more widely dehiscing anthers than those that are more hymenopteran pollinated (app. A). The choices of pairs were initially guided by the traditional taxonomy, but the provisional molecular phylogenies support all the choices.

\section{Pollen Packaging Census on the Exception to the Rule}

Among only the dried specimens, closely related Penstemon strictus (hymenopteran pollinated) and Penstemon barbatus (hummingbird pollinated) are essentially tied in how wide their anthers open. Because this pair was of particular interest, we followed the dehiscence of the anthers throughout the lives of individual flowers, that is, pollen packaging as opposed to pollen dispensing. We labeled unopened flower buds in the evening. The buds belonged to at least eight plants of each species growing near each other along U.S. Highway 50, Gunnison County, Colorado. Starting the following morning, flower opening time was recorded, and each of the four anthers in a flower was scored as closed, partially open (pollen was visible, but the anther was $<60 \%$ dehisced), or fully open. We continued scoring at 2-h intervals until dark and into the following day until all anthers had dehisced.

\section{Pollen and Ovule Production}

For each of 50 species, we collected 18-20 unopened flowers from different plants. Each ovary was preserved in ethanol in a microcentrifuge tube. The anthers were allowed to dehisce in another tube. Later, we counted ovules under a dissecting scope and estimated pollen numbers with a particle counter. In addition, we measured the length of six dried anther locules for each species and took an average as a measure of anther size. We used multiple regression to summarize the relationships among pollinator type, ovule number, locule length, and pollen number.

\section{Results}

Dispensing

The large variation in anther morphology among penstemons paralleled variation in pollen dispensing in the velvet assay. Without phylogenetic correction, variation among species overwhelmed differences between bee- and birdpollinated species in the dispensing curves (nonsignificance of pollination syndrome in nested ANOVAs; table 1); however, comparing close relatives with different pollination syndromes revealed systematic trends.

We compared the two pollination systems within four taxonomic subgroups where separate pollinator shifts have happened: (1) Penstemon laetus versus Penstemon rostriflorus, (2) Penstemon strictus versus Penstemon barbatus, (3) Penstemon gentryi versus Penstemon kunthii, and (4) Keckiella breviflora versus Keckiella ternata. The proportion of grains released in the first $4.5 \mathrm{~h}$ of sampling was higher for the bee-pollinated member of each pair, which would be expected for anthers that dispense more gradually (significant in pairs 2 and 3). Similarly, the half-life of anthers was shorter for hummingbird-pollinated species, except in Keckiella, where it was very similar in the two species (significant in pairs 1 and 3). These results suggest more restrictive dispensing by bee-adapted species. With only four comparisons, paired $t$-tests were marginally significant for both variables, log-transformed half-life $(t=$ $1.68, P=.09)$ and arcsine-square root-transformed proportion of grains presented in first $4.5 \mathrm{~h}(t=2.09, P=$ .06).

In micrographs (app. A), dry anther morphology is concordant with the velvet results. For example, $P$. gentryi has canoe-shaped anthers such that pollen deep in the anther could be resistant to removal, whereas $P$. kunthii has more platter-shaped anthers that shed their pollen more easily (block A, app. A). The pair P. strictus and P. barbatus presents a special case (block J, app. A). The dry anthers of these species do not seem to reflect the faster dispensing by $P$. barbatus.

Having only four pairs of close relatives provides low statistical power to generalize differences between syndromes across penstemons. However, velvet assays correspond well to dehiscence ranks. The linear regressions of both of the dispensing variables on the rank of dehiscence are significant in the predicted direction (fig. 1): for the log-transformed half-life, $r^{2}=0.657, F=120.8$, $P<.001$; and for the arcsine-square root-transformed proportion of grains released in 10 samples, $r^{2}=0.869$, $F=378.6, P<.001$. The dehiscence ranks can thus be used as proxies for pollen dispensing. 

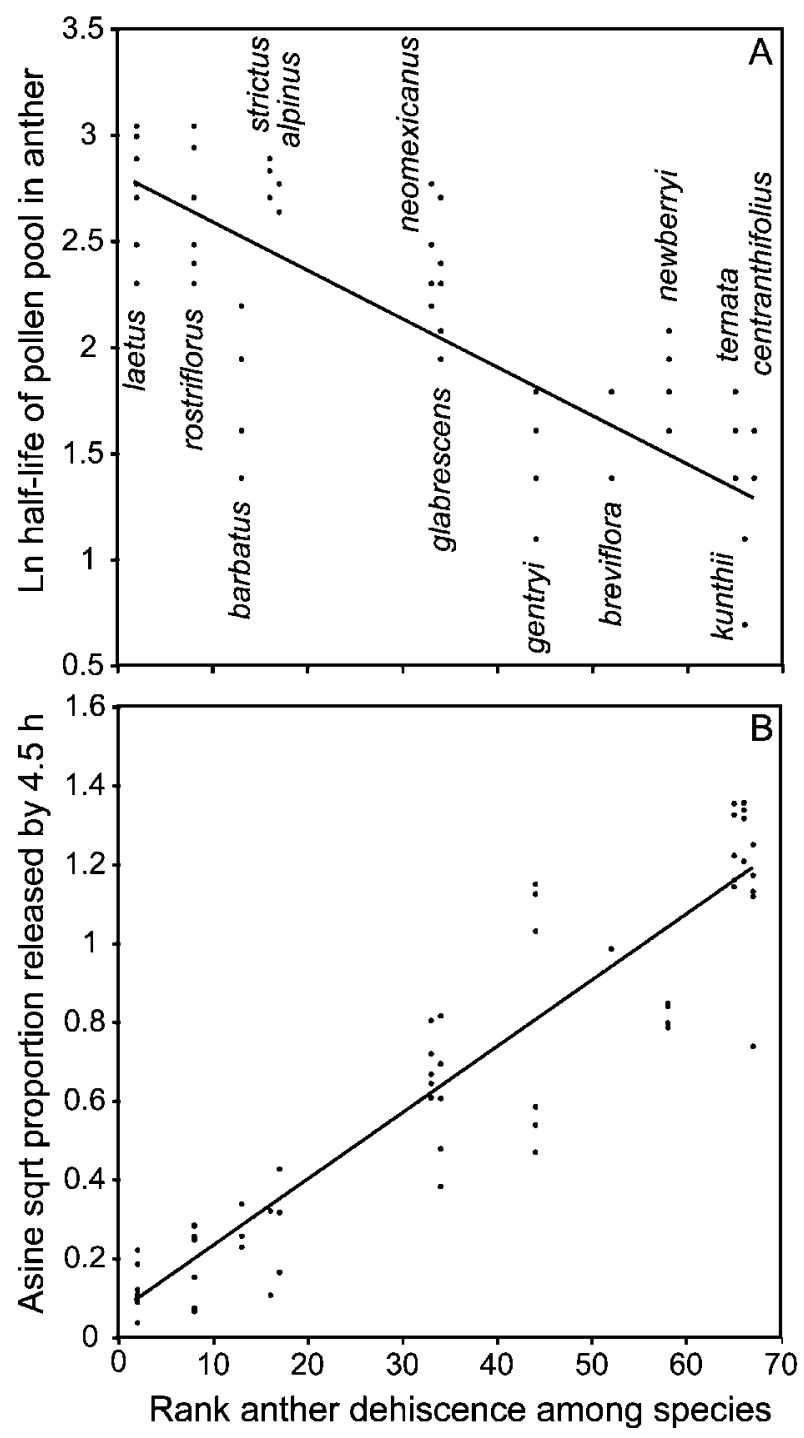

Figure 1: Regression of two variables of dispensing (measured with the velvet method) on the rank of anther dehiscence of 13 species of penstemons. The species are arranged in the $X$-axes according to their dehiscence rank among 69 species so that species on the right have anthers that dehisce wider. Points represent replicates within each species. $A$, The half-life of pollen grains is shorter for species with widely opening anthers. $B$, The proportion of grains presented by $4.5 \mathrm{~h}$ is higher for anthers with wider dehiscence.

\section{Dehiscence Rank Comparison between Bee-and Bird-Pollinated Flowers}

Using dehiscence ranks, we compared blocks of closely related species that represent separate originations of bird pollination (table 2). Anthers are illustrated by taxon block in appendix A. Where the closest match is not resolved, we used conservative combinations of species. A paired $t$ - test is highly significant: the anthers of hummingbirdpollinated species dehisce more than those of their beepollinated relatives ( $t=4.3, P=.0005, n=18$ pairs). To be more cautious, we repeated this analysis considering close differences in ranks (5 or less) as ties and performed a Wilcoxon signed-ranks test. It also showed significantly wider dehiscence in bird-pollinated species $(P<.005$, $n=15$ ). Finally, for a phylogenetically cleaner comparison, we repeated the analysis using only the 10 pairs in table 2 with clear sister taxa. Again, we found wider anther dehiscence in bird-pollinated species (paired $t=4.2$, $P=.002, n=10$ pairs).

\section{Pollen Packaging Census on the Exception to the Rule}

We found no differences between $P$. strictus and P. barbatus flowers in the length of time from the first anther opening to the last $(13.9 \pm 1.84 \mathrm{~h}$ [SE], $n=20$ for P. strictus; $17.2 \pm 1.66 \mathrm{~h}, n=18$ for $P$. barbatus; $t=1.33$, df $=$ $36, P=.192$ ), but further analysis showed that their diel schedules produced meaningful differences in pollen packaging. Penstemon strictus had more censuses in which new pollen became available for removal than $P$. barbatus: nine of the P. strictus flowers had new pollen in two censuses and 11 had new pollen in three censuses, whereas 17 of the P. barbatus flowers had new pollen in two censuses and only one had new pollen in three censuses (Fisher's exact test, $P=.001$ ). Moreover, $P$. strictus anthers were recorded as being partially open $25 \%$ of the time, while $P$. barbatus anthers were never partially open (Fisher's exact test with each anther as a replicate, $P<.001)$. These patterns indicate that $P$. strictus achieved more gradual pollen packaging during the periods when pollinators were active. The long duration of dehiscence in $P$. barbatus arose because flowers frequently opened two anthers late on one day, roughly simultaneously, and the other two early the next day. Those times roughly coincide with peaks of hummingbird activity.

\section{Pollen Production Patterns}

The log of pollen production (across 50 species) was positively related to the number of ovules per flower (logtransformed; standardized partial $b^{\prime}=0.599, P<.0001$ ) and to locule length $\left(b^{\prime}=0.246, P=.033\right)$ but not to bee versus bird pollination $\left(b^{\prime}=-0.099, P=.394\right)$. In a separate bivariate analysis, pollen production was not related to the dehiscence rank of anthers $(r=0.028$, $P=.28, n=52)$.

When we considered only blocks of closely related species with different pollinators, the number of pollen grains in a flower again did not differ between bee- and birdpollinated species (paired $t=1.16$, one-tailed $P=.277$, 
Table 2: Comparison of anther dehiscence ranks in closely related pairs of Penstemon and Keckiella species with contrasting pollinators

\begin{tabular}{lllcl}
\hline Pair & \multicolumn{1}{c}{ Bird-pollinated species } & \multicolumn{1}{c}{ Bee-pollinated species } & $\begin{array}{c}\text { Rank } \\
\text { difference }\end{array}$ & $\begin{array}{c}\text { Ranks as predicted: } \\
\text { bee }<\text { bird? }\end{array}$ \\
\hline A & P. kunthii & P. gentryi & 22 & Yes \\
B & P. pinifolius & P. glabrescens & 26 & Yes \\
C & P. centranthifolius & P. patens & 29 & Yes \\
D & P. rostriflorus & P. laetus & 6 & Yes, but close \\
E & P. newberryi & P. davidsonii & 5 & Yes, but close \\
F & P. utahensis & P. confusus & 18 & Yes \\
G & All bird-pollinated Keckiella species & All bee-pollinated Keckiella species & 19.8 & Yes \\
H & P. lanceolatus & P. dasyphyllus & 14 & Yes \\
I & P. hartwegii & P. gentianoides & 20 & Yes \\
J & P. barbatus & E.g., P. strictus & -6.5 & No, but close \\
K & P. labrosus & E.g., P. speciosus & 3.5 & Yes, but close \\
L & P. cardinalis & E.g., P. neomexicanus & 6.5 & Hard to compare \\
M & P. eatonii & E.g., P. alpinus & 10.5 & Yes \\
N & P. pseudospectabilis & P. spectabilis & 41 & Yes \\
O & P. harvardii & All bee-pollinated species & 26.7 & Yes \\
P & P. fasciculatus & All bee-pollinated species & 24.7 & Yes \\
Q & P. baccharifolius & All bee-pollinated species & -10.3 & No \\
R & P. floridus & P. palmeri & -5 & No, but close \\
\hline
\end{tabular}

Note: Each row represents a separate origination of hummingbird pollination. Appendix A in the online edition of the American Naturalist gives details on blocking and pictures of anthers. The rank difference shows the result of subtracting the rank of the bee-pollinated species (or a mean rank in case of uncertain closest relatives) from the rank of the bird-pollinated species. The last column shows whether the pair conforms to the prediction that the bee-pollinated species would have more restricted pollen presentation (i.e., a lower dehiscence rank).

$n=9$ pairs). The mean number of grains ranged from 100,500 to 428,100 for bee-pollinated species, and from 93,600 to 255,800 for bird-pollinated species.

\section{Discussion}

Pollen presentation in penstemons has evolved to match the type of pollinator. There is so much phylogenetic conservatism within subgroups that we cannot consider a particular anther morphology as a "bee type" or "bird type," but in phylogenetically controlled comparisons, hymenopteran-adapted species present pollen more gradually than their hummingbird-adapted relatives (table 2). We believe that this pattern is most probably caused by the differences in pollen transfer efficiency that arise from the differences in grooming behavior. This interpretation is consistent with direct measures of pollen transfer by Castellanos et al. (2003). Although those studies did not show that bees would remove more pollen than birds, the bee data were restricted to nectar-collecting visits. Common penstemon-visiting Hymenoptera other than nectaring bumblebees (pollen-collecting Bombus, Osmia, and Pseudomasaris wasps) are certain to remove more pollen from anthers and are less likely to deliver it to stigmas. Castellanos et al. (2003) did find that birds have flatter pollen carryover curves than bees, which is consistent with the idea that it is less wasteful for a plant to put large amounts of pollen on a bird than on a less efficient bee. This conclusion is further supported by the results in this article: hymenopteran-pollinated penstemons seem adapted for miserly pollen donation.

Adaptation to bird pollination loosens the restrictions on pollen dispensing, but it does not change pollen production per flower. Pollen production is evolutionarily labile, but it is correlated with flower size and not with the type of pollinator. The independence of pollen production and pollinator type simplifies the interpretation of different dispensing schedules as evolutionary tactics to maximize successful pollination by different animals.

In general, gradual or restricted pollen presentation can be achieved by various mechanisms (Lloyd and Yates 1982). Pollen may be dispensed from an anther, or there may be staggered maturation of pollen packages. Castellanos (2003) described pilot studies of pollen packaging among anthers in Penstemon. Although no tidy statistical pattern has emerged, the comparison of bird-pollinated Penstemon barbatus with bee-pollinated Penstemon strictus reported above showed that presentation of pollen packages is more simultaneous in the former, which is consistent with our theories. It is possible that dispensing by anthers dominates the evolution of pollen presentation in penstemons. Anther-level dispensing provides a shortterm plasticity that packaging does not. Gradual dispensing, by definition, allows for the facultative accumulation 
of grains in anthers when visitation rates are unusually low in a population that normally receives many visits (Harder and Thomson 1989; Harder and Barclay 1994).

Despite the pattern of more gradual dispensing in beeadapted species, there was great residual variation among the 13 penstemons studied. Some hummingbird-pollinated species released between $77 \%$ and $93 \%$ of their grains by the fifth hour of sampling, whereas Penstemon rostriflorus dispensed only $5 \%$ of its grains in that time. Penstemon rostriflorus has saccate anthers (characteristic of subgenus Saccanthera; block D, app. A), a morphology that restricts dispensing. Another source of variation in dispensing could be secondary pollen presentation on anther hairs, as could be the case for P. strictus (block J, app. A), a species with relatively broad dehiscence but gradual dispensing. Its close relative, the bird-pollinated P. barbatus, lacks hairs. Dense hairs around the anther dehiscence line could help restrict removal. This could explain why our velvet assays and dehiscence rank scores did not agree in this species pair. It is also possible that hairy anthers restrict pollen removal by bees that buzz flowers; a dense pubescence could inhibit the transfer of vibrational energy to the anther. The role of hairs needs further testing. Members of the traditional subgenus Dasanthera and the genus Nothochelone have very wooly anthers, and their functional dispensing might be more complex than suggested by dehiscence rank.

It is difficult to assess the generality of our findings; few other studies have quantified pollen presentation, and none has taken a comparative approach. Harder (1990b) found restricted pollen dispensing by anthers only in two out of six species, although some degree of staggered packaging was always present. In flowers of Brassica napus, Bell and Cresswell (1998) found dispensing from anthers and speculated that pollen was disseminated at the same rate that it was dispensed because pollen did not accumulate in anthers. This implies that dispensing was effectively limiting pollen delivery, as pollen presentation theory predicts in plants with high visitation rates. Conner et al. (2003) speculated that selection for restricted pollen removal might explain stasis in anther height dimorphism in the Brassicaceae. The flowers are usually generalists visited by small insects, and single-visit removal is reduced by anther dimorphism.

An example of extreme dispensing is provided by poricidal anthers that deliver pollen only onto bees capable of buzzing them. Harder and Barclay (1994) reported that in several buzz-pollinated plants, poricidal anthers are "tuned out" beyond the maximum vibration frequencies that bees can produce, so that removal is controlled. In buzz-pollinated Rhexia virginica, Larson and Barrett (1999) found gradual dispensing over three visits to a flower. Visits to their study plants were very infrequent, so about $50 \%$ of pollen grains remained untouched in flowers. They found strong pollen limitation of fecundity, which suggests that the combination of low visitation and gradual dispensing leads to reduced fertility.

\section{Floral Rewards and Pollen Presentation}

Controlled presentation of pollen cannot dictate the exact pattern of pollen dispersal. Gradual dispensing can put an upper limit on the grains available for removal at any moment, but removal also depends on pollinator behavior and frequency (Harder 1990a). In turn, behavioral patterns depend on the pollinator species and the conduct of the visitor at the flower. Pollen collectors, for example, may be able to force more pollen out of the anthers than is exposed, using buzzing behaviors and manipulation of anthers with mouthparts or forelegs. Alternatively, a small visitor that hardly contacts the anthers might reach the nectaries but leave available pollen in the anthers.

More importantly, the optimal schedule of pollen presentation is expected to be coupled with the production of rewards that influence pollinator behaviors (Harder and Thomson 1989). For instance, the amount of nectar available in the flower can determine the length of a visit or the number of flowers visited in the plant, which then could affect pollen removal (Harder 1990b; Cresswell and Galen 1991; Hodges 1995). We have not directly linked nectar secretion with pollen dispensing, but we have studied the nectar offerings of penstemons (Castellanos et al. 2002; Wilson et al. 2006). Penstemon speciosus, for example, dynamically replenishes nectar in response to emptying, such that a full load of nectar is produced in less than 3 $\mathrm{h}$, and some fresh nectar is available almost continuously. Furthermore, bee-adapted $P$. strictus replenishes nectar faster than bird-adapted P. barbatus, consistent with the more gradual pollen presentation by $P$. strictus. More detailed measurements are necessary to establish whether pollen presentation is synchronized with nectar offerings. In a case where the reward is pollen itself, pollen-collecting honeybees adjust their visitation to the rate of pollen dispensing in Cistus salvifolius (Nansen and Korie 2000).

\section{Conclusion}

The pattern of differential pollen presentation we found is consistent with a hypothesis of selection caused by malemale competition. In pollination, such competition is most important in species where seed set is not pollen limited and many grains compete for reaching stigmas (Charnov 1979) or where pollen grains are not evenly distributed among stigmas (Stanton 1994). Floral strategies for attracting pollinators (showy petals, rich nectar) and encouraging their fidelity and constancy (distinctive color patterns or handling requirements) have been interpreted 
as consequences of male-male competition (e.g., Bell 1985; Stanton et al. 1986; Galen 1992). Our work shows how mechanisms for controlled pollen delivery to pollinators can also be strategies for maximizing pollen dispersal, at least in plants that have the physiological and anatomical potential for fine-tuning the dispensing or packaging of grains (Lloyd and Yates 1982; Lloyd 1984). Penstemon anthers can dehisce at different speeds and to various widths and can thus accommodate the presentation of grains to the shape of the male fitness gain curve that corresponds to the pollinators of the species. The level of competition for stigmas might be variable among penstemon populations, but the shape of the male gain curve should consistently depend on whether the species is bee or bird pollinated (see Yund 1998). Thus, anthers have diverged in the schedule of pollen presentation and the morphology of dehiscence.

\section{Acknowledgments}

We thank V. Vidal for invaluable help with velvet. P. Elcock, A. Leslie, N. Saleh, V. Vidal, and A. Wong helped count pollen, M. Danielczyk helped with ovules, and R. Chao helped with the SEM. A. Agrawal, H. Rodd, and two anonymous reviewers provided comments to previous versions of the manuscript, and S. Armbruster advised us on comparative methods. Financial support was provided by the National Science Foundation (DEB-9707330, DBI9987953), the Canadian Natural Sciences and Engineering Research Council, and the Ontario Graduate Scholarship program.

\section{Literature Cited}

Arnold, S. J. 1994. Is there a unifying concept of sexual selection that applies to both plants and animals? American Naturalist 144(suppl.): S1-S12.

Badyaev, A. V., and G. E. Hill. 2003. Avian sexual dichromatism in relation to phylogeny and ecology. Annual Reviews of Ecology and Systematics 34:27-49.

Bell, G. 1985. On the function of flowers. Proceedings of the Royal Society of London B 224:223-265.

Bell, S. A., and J. E. Cresswell. 1998. The phenology of gender in homogamous flowers: temporal change in the residual sex function of flowers of oil-seed rape (Brassica napus). Functional Ecology 12:298-306.

Castellanos, M. C. 2003. The evolution of transitions between pollination modes in Penstemon. $\mathrm{PhD}$ diss. University of Toronto.

Castellanos, M. C., P. Wilson, and J. D. Thomson. 2002. Dynamic nectar replenishment in flowers of Penstemon (Scrophulariaceae). American Journal of Botany 89:111-118.

2003. Pollen transfer by hummingbirds and bumblebees, and the divergence of pollination modes in Penstemon. Evolution 57:2742-2752.

Charnov, E. L. 1979. Simultaneous hermaphroditism and sexual se- lection. Proceedings of the National Academy of Sciences of the USA 76:2480-2484.

. 1982. The theory of sex allocation. Princeton University Press, Princeton, NJ.

Conner, J. K., A. M. Rice, C. Stewart, and M. T. Morgan. 2003. Pattern and mechanisms of selection on a family-diagnostic trait: evidence from experimental manipulation and lifetime fitness selection gradients. Evolution 57:480-486.

Cresswell, J. E., and C. Galen. 1991. Frequency-dependent selection and adaptive surfaces for floral character combinations: the pollination of Polemonium viscosum. American Naturalist 138:13421353.

Crosswhite, F. S., and C. D. Crosswhite. 1981. Hummingbirds as pollinators of flowers in the red-yellow segment of the color spectrum, with special reference to Penstemon and the "open habitat." Desert Plants 3:156-170.

Cruden, R. W. 1972. Pollinators in high-elevation ecosystems: relative effectiveness of birds and bees. Science 176:1439-1440.

- 1976. Intraspecific variation in pollen-ovule ratios and nectar secretion: preliminary evidence of ecotypic adaptation. Annals of the Missouri Botanical Garden 63:277-289.

Datwyler, S. L., and A. D. Wolfe. 2004. Phylogenetic relationships and morphological evolution in Penstemon subg. Dasanthera (Veronicaceae). Systematic Botany 29:165-176.

Freeman, C. E., J. S. Harrison, J. P. Janovec, and R. Scogin. 2003. Inferred phylogeny in Keckiella (Scrophulariaceae) based on noncoding chloroplast and nuclear ribosomal DNA sequences. Systematic Botany 28:782-790.

Galen, C. 1992. Pollen dispersal dynamics in an alpine wildflower, Polemonium viscosum. Evolution 46:1043-1051.

Harder, L. D. 1990a. Behavioral responses by bumble bees to variation in pollen availability. Oecologia (Berlin) 85:41-47.

- $1990 \mathrm{~b}$. Pollen removal by bumble bees and its implications for pollen dispersal. Ecology 71:1110-1125.

Harder, L. D., and R. M. R. Barclay. 1994. The functional significance of poricidal anthers and buzz pollination: controlled pollen removal from Dodecatheon. Functional Ecology 8:509-517.

Harder, L. D., and J. D. Thomson. 1989. Evolutionary options for maximizing pollen dispersal of animal-pollinated plants. American Naturalist 133:323-344.

Harder, L. D., and W. G. Wilson. 1994. Floral evolution and male reproductive success: optimal dispensing schedules for pollen dispersal by animal-pollinated plants. Evolutionary Ecology 8:542559.

- 1998. Theoretical consequences of heterogeneous transport conditions for pollen dispersal by animals. Ecology 79:2789-2807.

Hodges, S. A. 1995. The influence of nectar production on hawkmoth behavior, self-pollination, and seed production in Mirabilis multiflora (Nyctaginaceae). American Journal of Botany 82:197-204.

Hosken, D. J., and P. Stockley. 2004. Sexual selection and genital evolution. Trends in Ecology \& Evolution 19:87-93.

Janzen, D. H. 1977. Note on optimal mate selection by plants. American Naturalist 111:365-371.

Kearns, C. A., and D. W. Inouye. 1993. Techniques for pollination biologists. University Press of Colorado, Niwot.

Knuth, P. 1909. Handbook of flower pollination. Vol. 3. Clarendon, Oxford.

Larson, B. M. H., and S. C. H. Barrett. 1999. The ecology of pollen limitation in buzz-pollinated Rhexia virginica (Melastomataceae). Journal of Ecology 87:371-381. 
LeBuhn, G., and G. J. Anderson. 1994. Anther tripping and pollen dispensing in Berberis thunbergii. American Midland Naturalist 131:257-265.

LeBuhn, G., and K. Holsinger. 1998. A sensitivity analysis of pollendispensing schedules. Evolutionary Ecology 12:111-121.

Lloyd, D. G. 1984. Gender allocations in outcrossing cosexual plants. Pages 277-300 in R. Dirzo and J. Sarukhán, eds. Perspectives on plant population ecology. Sinauer, Sunderland, MA.

Lloyd, D. G., and M. A. Yates. 1982. Intrasexual selection and the segregation of pollen and stigmas in hermaphrodite plants, exemplified by Wahlenbergia albomarginata (Campanulaceae). Evolution 36:903-913.

Lodewick, R., and K. Lodewick. 1999. Key to the genus Penstemon and its related genera in the tribe Cheloneae (Scrophulariaceae). Lodewick, Eugene, OR.

Nansen, C., and S. Korie. 2000. Determining the time delay of honey bees (Apis mellifera) foraging response to hourly pollen release in a typical pollen flower (Cistus salvifolius). Journal of Apicultural Research 39:93-101.

Percival, M. S. 1955. The presentation of pollen in certain angiosperms and its collection by Apis mellifera. New Phytologist 54: 353-368.

Queller, D. 1997. Pollen removal, paternity, and the male function of flowers. American Naturalist 149:585-594.

Rademaker, M. C. J., T. J. de Jong, and P. G. L. Klinkhamer. 1997. Pollen dynamics of bumble-bee visitation on Echium vulgare. Functional Ecology 11:554-563.

Robertson, A. W., and D. G. Lloyd. 1993. Rates of pollen deposition and removal in Myosotis colensoi. Functional Ecology 7:549-559.

Sargent, R. D. 2003. Seasonal changes in pollen-packaging schedules in the protandrous plant Chamerion angustifolium. Oecologia (Berlin) $135: 221-226$.

Stanton, M. L. 1994. Male-male competition during pollination in plant populations. American Naturalist 144(suppl.): S40-S68.

Stanton, M. L., A. A. Snow, and S. N. Handel. 1986. Floral evolution: attractiveness to pollinators increases male fitness. Science 232: $1625-1627$.

Thomson, J. D. 2003. When is it mutualism? American Naturalist 162(suppl.):S1-S9.
Thomson, J. D., and S. C. H. Barrett. 1981. Temporal variation of gender in Aralia hispida Vent (Araliaceae). Evolution 35:10941107.

Thomson, J. D., and B. A. Thomson. 1989. Dispersal of Erythronium grandiflorum pollen by bumble bees: implications for gene flow and reproductive success. Evolution 43:657-661.

1992. Pollen presentation and viability schedules in animalpollinated plants: consequences for reproductive success. Pages 124 in R. Wyatt, ed. Ecology and evolution of plant reproduction. Chapman \& Hall, New York.

Thomson, J. D., P. Wilson, M. Valenzuela, and M. Malzone. 2000. Pollen presentation and pollination syndromes, with special reference to Penstemon. Plant Species Biology 15:11-29.

Warner, R. R., D. Y. Shapiro, A. Marcanato, and C. W. Petersen. 1995. Sexual conflict: males with highest mating success convey the lowest fertilization benefits to females. Proceedings of the Royal Society of London B 262:135-139.

Wedell, N., M. J. G. Gage, and G. A. Parker. 2002. Sperm competition, male prudence and sperm-limited females. Trends in Ecology \& Evolution 17:313-320.

Willson, M. F. 1979. Sexual selection in plants. American Naturalist 113:777-790.

Wilson, P., J. D. Thomson, M. L. Stanton, and L. P. Rigney. 1994. Beyond floral Batemania: gender biases in selection for pollination success. American Naturalist 143:283-296.

Wilson, P., M. C. Castellanos, J. N. Hogue, J. D. Thomson, and W. S. Armbruster. 2004. A multivariate search for pollination syndromes among penstemons. Oikos 104:345-361.

Wilson, P., M. C. Castellanos, A. Wolf, and J. D. Thomson. 2006. Shifts between bee- and bird-pollination among penstemons. In N. M. Waser and J. Ollerton, eds. Specialization and generalization in pollination systems. University of Chicago Press, Chicago.

Yund, P. O. 1998. The effect of sperm competition on male gain curves in a colonial marine invertebrate. Ecology 79:328-339.

Associate Editor: Judith L. Bronstein Editor: Jonathan B. Losos 


\title{
Appendix A from M. C. Castellanos et al., "Anther Evolution: Pollen Presentation Strategies When Pollinators Differ"
}

\author{
(Am. Nat., vol. 167, no. 2, p. 288)
}

\section{Images of Penstemon Anthers and Phylogenetic Relationships}

\author{
There are great variations within the genus Penstemon as regards the staminode, \\ as well as with reference to the nectaries, and these are obviously related to the \\ method of pollination.... In order to explain all these relations, and also the \\ different methods of anther dehiscence, a comparative oecological research on \\ numerous species is a desideratum. (Knuth 1909, pp. 184-185)
}

What follows is a block-by-block explanation of how the anthers contrast and the evidence behind the species pairs that represent separate origination of hummingbird pollination among penstemons. The letters correspond to the blocks as illustrated in figure A1. We frequently refer to the internal transcribed spacer (ITS) phylogeny shown in figure A2, which is a pruned version of the phylogeny for penstemons. A summary of the taxonomy is found in Lodewick and Lodewick (1999).

(A) Bee-pollinated $P$. gentryi anthers open much less wide than closely related bird-pollinated $P$. kunthii (both traditionally in subsection Campanulati). The phylogeny places these species together with the origination of hummingbird pollination as separate from all others.

(B) Penstemon glabrescens, $P$. crandallii, and many other bee-pollinated species in the same subsection (Caespitosi) open narrowly compared with the wide-dehiscent bird-pollinated $P$. pinifolius. The ITS tree confirms the relationship of $P$. pinifolius to this group. Traditional taxonomists had separated $P$. pinifolius from Caespitosi and sometimes listed it with the likes of $P$. fasciculatus, but Penstemon specialist F. Crosswhite believed that it was never properly placed (Crosswhite and Crosswhite 1981).

(C) Both the ITS phylogeny and the traditional taxonomy place the bee-pollinated $P$. patens as related to the bird-pollinated $P$. centranthifolius. The exact relationship is not crucial because the anthers of $P$. centranthifolius open wider than those of any bee-pollinated penstemon.

(D) Penstemon rostriflorus is the only bird-pollinated species in one of the traditional subgenera (Saccanthera), and it has anthers with a gaping mouth compared with P. laetus and all other bee-pollinated species except $P$. neotericus (not shown), which opens about as wide as P. rostriflorus. For statistical purposes, we compared $P$. rostriflorus with the mean of all bee-pollinated Saccanthera for which we had data. ITS indicates this origination as certainly separate from all others.

(E) The ITS tree confirms a separate origination of hummingbird pollination within another traditional subgenus (Dasanthera). It is debatable whether $P$. newberryi and the other hummingbird-pollinated species in the subgenus $P$. rupicola are monophyletic, so we only count one of them. In this group, the anthers are very woolly (possibly a relevant fact if pollen is secondarily presented on the hairs), and even the bee-pollinated $P$. davidsonii dehisces wide. However, there is more of an edge to the anthers of $P$. davidsonii than in the more bird-pollinated $P$. newberryi, and in $P$. davidsonii the anthers remain held together after dehiscence, whereas in P. newberryi the mature anthers are held more horizontally (Datwyler and Wolfe 2004).

(F) Based on close morphological similarity and biogeography, the bee-pollinated $P$. confusus seems to be related to bird-pollinated species such as $P$. utahensis, a species with anthers that open less wide. Unfortunately, we lack complete DNA data on $P$. utahensis despite many attempts, so it is not shown in figure A2, but it was found to be a separate origination by Wilson et al. (2005). This appears to be a second origination of hummingbird pollination in subsection Centranthifolii, aside from $P$. centranthifolius.

(G) All data agree that Keckiella is monophyletic and that hummingbird pollination must have arisen 
there separately from the originations within Penstemon itself. There are four species of bee-pollinated Keckiella, all of which have less open anthers than the three bird-pollinated species. The bee-pollinated Keckiella rothrockii jacintensis has markedly narrow dehiscence. Freeman et al. (2003) give a phylogeny with two originations of hummingbird pollination within Keckiella. Our studies with ITS allow for two equivocal ancestral character reconstructions, with either two originations of hummingbird pollination or an origination and a reversal. In this analysis, we conservatively lump all species in each pollinator type, using only one mean for each type.

(H) The bee-pollinated $P$. dasyphyllus opens by a small crack, whereas the bird-pollinated $P$. lanceolatus has anthers that nearly turn inside out. ITS data agrees on the traditional alliance (in section Chamaeleon) between these two species.

(I) The bee-pollinated P. gentianoides opens less wide than the more bird-pollinated $P$. hartwegii (traditionally in subsection Fasciculi). See comments under block P for doubts about the distinctness of the origination.

The following four pairs are closely related and belong to the traditional subgenus Habroanthus, a group with 43 bee-pollinated species and seven bird-pollinated species. ITS phylogenies suggest multiple originations of bird pollination in this subgroup, but it is not clear which bee-pollinated species are most appropriate for each comparison, and we lack complete data on many of the species. Using the species we have studied the most, we did four pairings for illustrative purposes of bee- and bird-pollinated species (pairs J-M). For statistical purposes, we compare each of the four independent bird-pollinated species with the mean of all beepollinated species in the subgenus. All are similar in how wide their anthers open, and the differences in how they open make assessing the differences in dispensing difficult.

(J) Contrary to our dehiscence ranks, the velvet data suggested that the bee-pollinated $P$. strictus dispenses more gradually than the bird-pollinated $P$. barbatus, so we could count this pair either as following predictions or as a tie, depending on whether the velvet data or the rank morphology is viewed as more definitive. Notice that recognizing fewer blocks and pooling with block M would actually make our results more significant.

(K) Mostly bee-pollinated $P$. speciosus has anthers that open narrowly compared with those of the birdpollinated P. labrosus. ITS indicates that P. labrosus is a separate origination in bootstrap trees, and constraining it to be with other bird-pollinated species lengthens the best tree.

(L) For the third pair, the bee-pollinated $P$. neomexicanus has unique anthers with a deep trough but wide-flared edges. Based on the gape measurement, it may present pollen more openly than the molecularly and biogeographically similar bird-pollinated $P$. cardinalis, although the latter species presents its pollen rather openly. It is hard to judge whether the pair follows or contradicts prediction. Penstemon cardinalis is not shown in figure A2, but it was a separate origination in the earlier data set of Wilson et al. (2005).

(M) The fourth pair, contrasting the bee-pollinated $P$. alpinus and the bird-pollinated $P$. eatonii, is close but in favor of the prediction, especially because $P$. eatonii has anthers that open more wide than most beepollinated species in the subgenus. The distinctness of the origination from that of $P$. barbatus is equivocal in the ITS data set (see comment in block J).

(N) Penstemon spectabilis seems to be more recalcitrant in presenting pollen than bird-and-bee-pollinated P. pseudospectabilis. The ITS phylogeny allows these two species as close relatives among many other choices, so our pairing in this case is based on taxonomy (traditionally subsection Peltanthera). In any case, the exact choice of a bee-pollinated species would not affect the result for this block.

(O) Traditional taxonomy places $P$. havardii in a separate subsection from $P$. centranthifolius (block C), though one might conceive that they are descended from a common ancestor that was hummingbird pollinated. However, the ITS tree dissuades us of this possibility, in which case $P$. havardii represents a separate origination of hummingbird pollination from those listed above, with the greatest doubt being that it could be nested within a group with narrow dehiscence (Habroanthus). It has anthers that open wider than any beepollinated penstemon. Which one is used for comparison does not matter, and we show P. buckleyi only as an example in figure A1 (similar to $P$. acuminatus, which is shown on the ITS tree). For our statistics, we compare $P$. havardii with all bee-pollinated species of penstemons.

(P) Bird-pollinated P. fasciculatus, which again has anthers that open wider than any bee-pollinated penstemon, could conceivably be a descendant from the same origination of hummingbird pollination as $P$. hartwegii (block I), but it is very dissimilar and more extreme in its reliance on hummingbirds. DNA data 
App. A from M. C. Castellanos et al., "Pollen Presentation and Sexual Selection"

suggest it may be compared with the bee-pollinated $P$. amphorellae. For statistical purposes, we compare it with all bee-pollinated species.

(Q) We have no match for the bird-pollinated P. baccharifolius. The way the anthers open along the connective suggests a relationship with species in block D (Saccanthera), but the DNA data argue strongly against such an alliance. It seems fairly deeply rooted in all DNA studies, but no firm conclusions can be made. For our statistics, we compare $P$. baccharifolius to all bee-pollinated penstemons.

(R) Finally, the widespread bee-pollinated P. palmeri may be a sister species to the endemic P. floridus, which is pollinated by both birds and bees. The ITS tree and the strong vegetative similarities confirm it. Penstemon palmeri has slightly less open, not wider open, anthers and therefore is a good candidate for defying the general pattern. This group needs further study. 


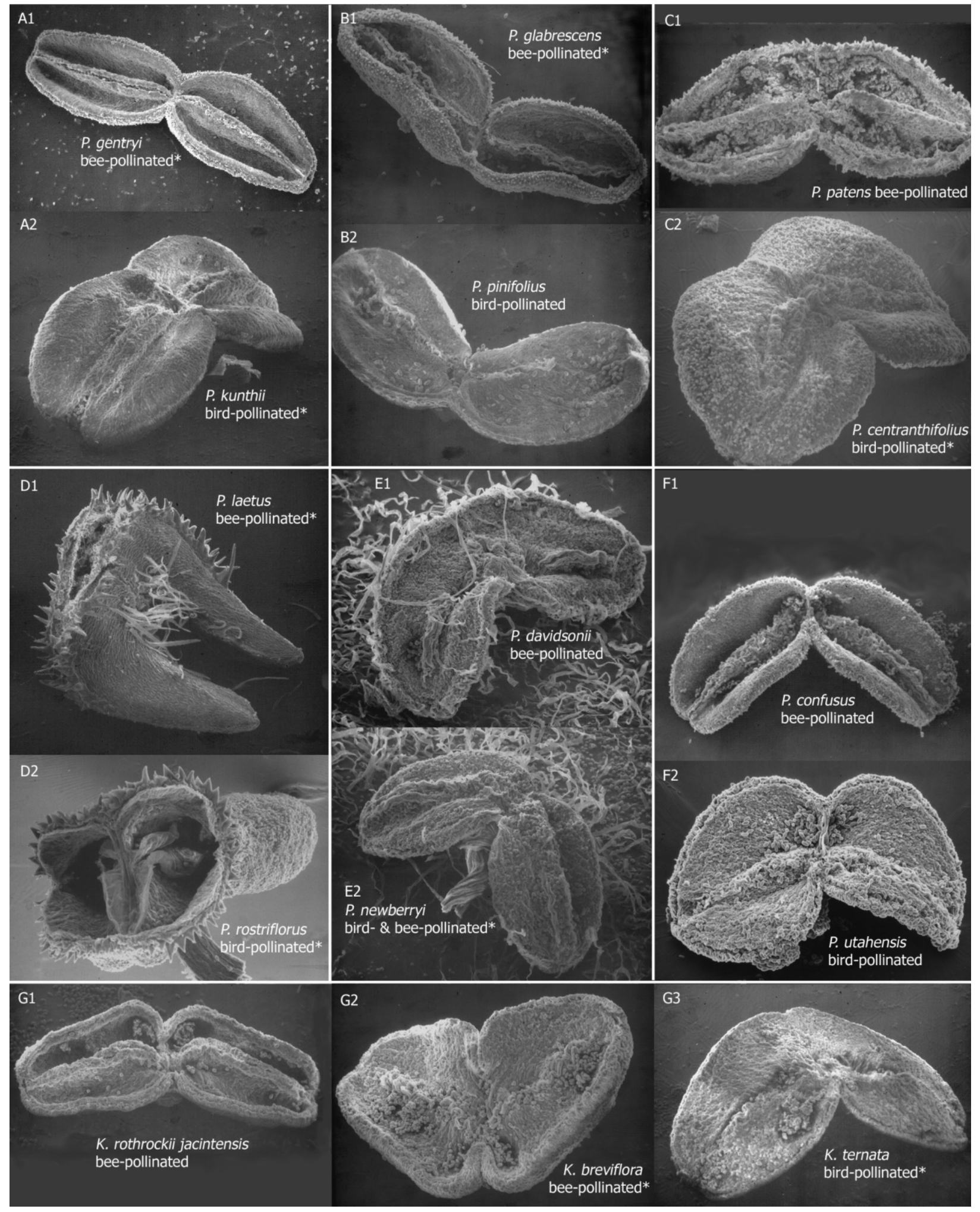



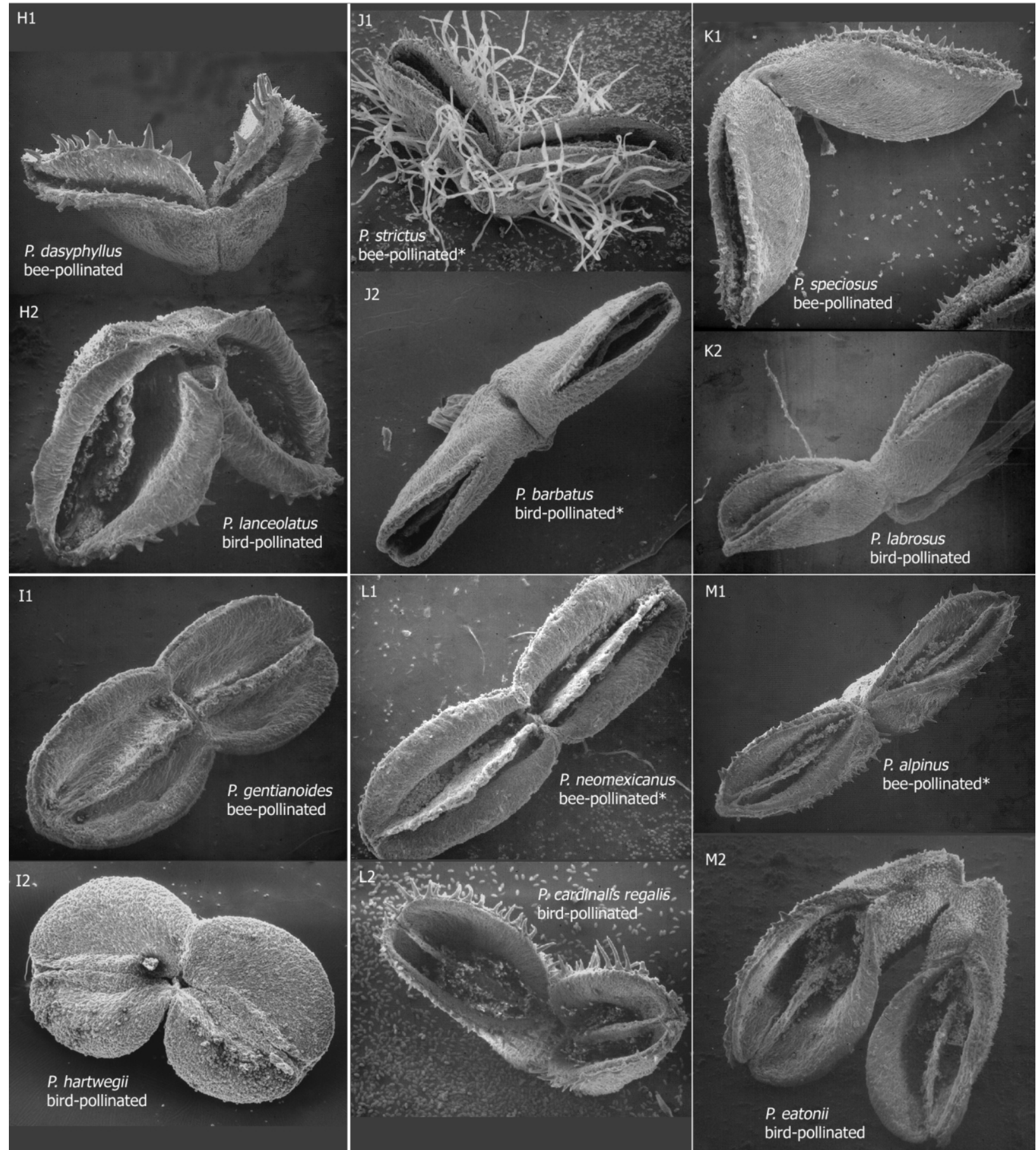

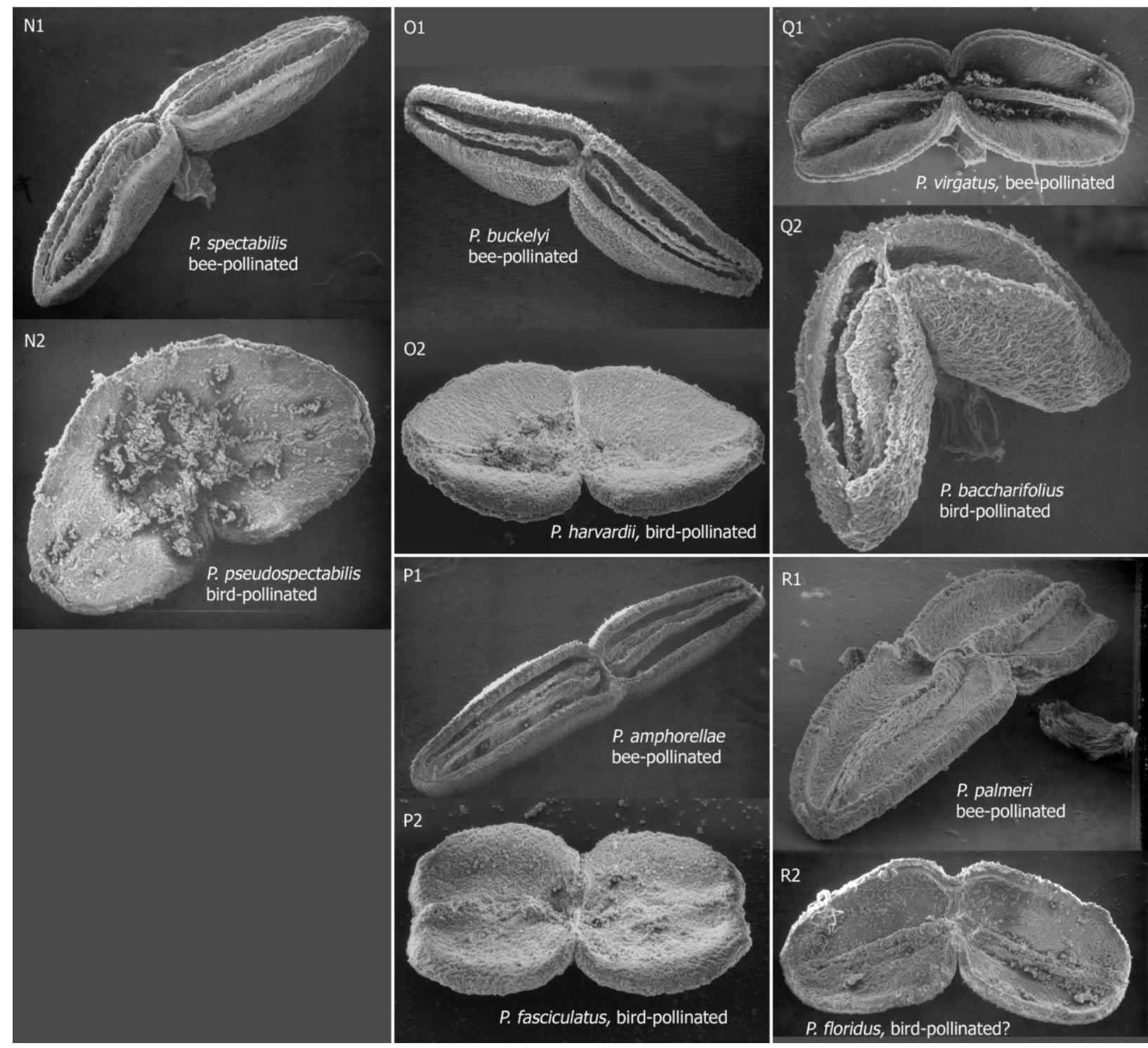

Figure A1: Scanning electron microscope images of fully dehisced Penstemon and Keckiella anthers, blocked by phylogenetic group. For the micrographs, pollen grains were removed with a paintbrush for better visibility of anther morphology. The anthers were coated with gold, $20 \mathrm{~nm}$ thick, using a Hummer II sputter coater, and photographed with a Jeol JSM 5400 scanning electron microscope. Asterisks mark species studied by the velvet method described in the text. Phylogenetic groups are separated by thick white lines. The letters correspond to the pairs in table 2 and to the phylogenetic blocks discussed above. 


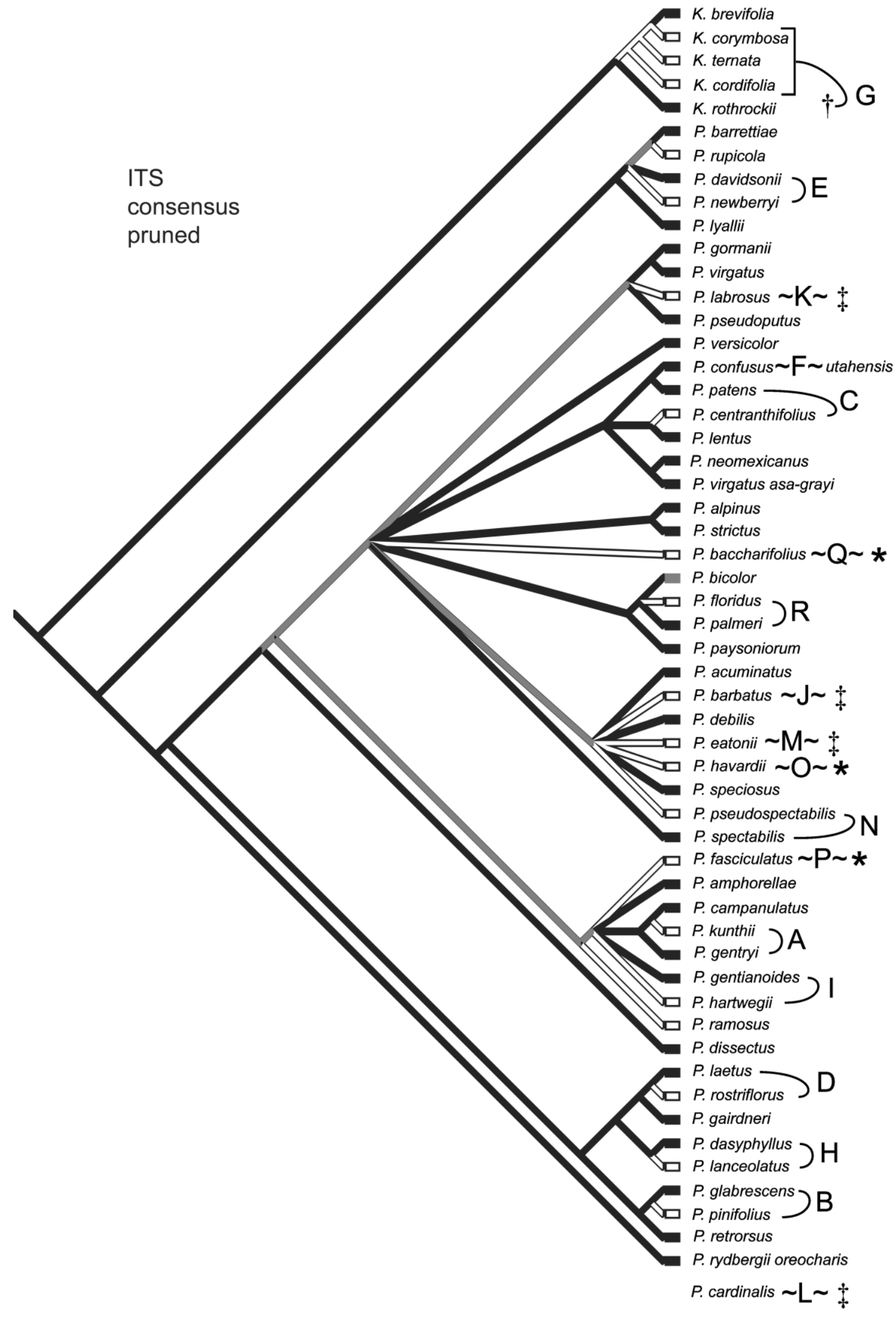


Figure A2: Phylogeny based on nuclear internal transcribed spacer (ITS) sequence data. A heuristic parsimony search was done on data including many more taxa. An Adams consensus was computed of 2,000 equally parsimonious trees, and irrelevant taxa were pruned out. Mapped onto the phylogeny is hummingbird pollination (white) versus insect pollination (black) based on flower color (there are several species that are intermediate one way or the other if one codes based on more floral characters). Equivocal lineages are shown in gray. Character mapping was done by parsimony of unordered character states. Although this is a pruned diagram and greatly underestimates the number of originations of hummingbird pollination among all penstemons, it is helpful in judging phylogenetic blocks for species whose anthers were studied (bold letters; see table 2). Arcs show the species pairs used for the analysis. Asterisks indicate comparisons using all bee-pollinated Penstemon species. Dagger indicates the comparison of the hummingbird-pollinated Keckiella species collectively to all bee-

pollinated Keckiella species collectively. Double daggers indicate comparisons using all bee-pollinated species in the subgenus Habroanthus. Penstemon cardinalis and Penstemon utahensis are shown for the sake of completeness, but their ITS data were not included in constructing the phylogeny (cf. Wilson et al. 2005). 


\title{
Appendix B from M. C. Castellanos et al., "Anther Evolution: Pollen Presentation Strategies When Pollinators Differ"
}

\author{
(Am. Nat., vol. 167, no. 2, p. 288)
}

\section{Measurement of Detailed Pollen Dispensing Schedules from Single Anthers}

To study pollen presentation by anthers in the most realistic way, it would be ideal to have actual pollinators visit the flowers, but it is not feasible to have them visit naturally at regular intervals and to later count the pollen grains on their bodies that came from a particular visit. Earlier trials with dead honeybee thoraxes provided a relatively "natural" removal of pollen, but it was extremely difficult to count grains distributed throughout the deep pubescence of those complex three-dimensional structures. The velvet method used here might not remove pollen grains in a way identical to that of a bee's body or a bird's head, but it provides a standardized way of measuring pollen presentation in all types of flowers.

The velvet method uses acetate velvet fabric cut into $4 \times 4$-mm squares (or smaller squares for flowers with narrow corollas). The velvet material consists of a woven backing with soft acetate fibers protruding at right angles to form the velvet's pile. The fibers are soluble in acetone, but the backing is not. We use fine forceps to insert the velvet pieces into the flower, brushing the anther once going in and once again pulling out. We attempt to always use the same amount of pressure, touching the anthers just firmly enough with the velvet that they move slightly but perceptibly upward. The velvet square with pollen on it is immediately put on a microscope slide; two drops of a solution of basic fuchsin in acetone are added to stain the pollen and to dissolve the velvet nap. After the acetone evaporates, a drop of melted glycerin jelly is added, and a glass cover slip is pushed down on it until the jelly cools (Kearns and Inouye 1993). Our jelly is also stained with fuchsin and contains phenol as a preservative. We later count all the grains on the slides at $\times 100$ magnification with a compound microscope equipped with a computer-controlled motorized stage.

For the samples reported here, a different piece of velvet was brushed against the anther every half hour from the time the anther started dehiscing in the morning until 2200 hours. Examples of the cumulative release of pollen are shown in figure B1. At the end of the sampling period, the anther was picked with forceps and preserved in ethanol. The remaining grains were counted later using an Elzone particle counter (Micromeritics, Norcross, GA).

We studied pollen presentation in potted Penstemon plants grown from field-collected seed and kept in a growth chamber under controlled temperature and humidity. Each plant studied had been in the chamber for a few days before the day of sampling. Unable to obtain flowering Penstemon barbatus plants in the greenhouse, we sampled from this species under less controlled conditions in the field. Four plants were kept indoors during sampling, in Irwin, Colorado, where the temperature and humidity were lower and more variable than in the environmental chambers used in the greenhouse. 


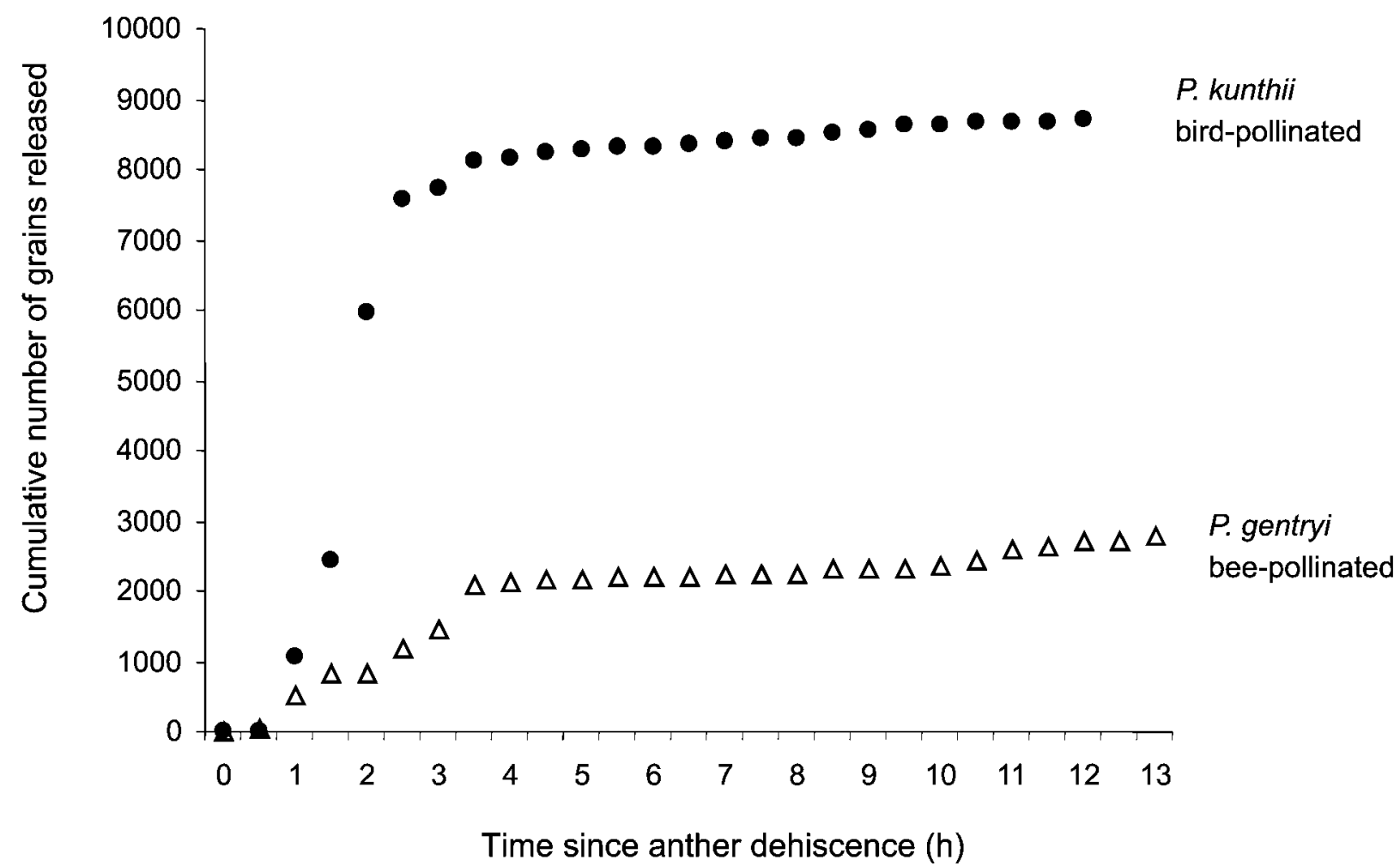

Figure B1: Examples of curves of cumulative numbers of pollen grains released during the sequence of velvet sampling, for one flower of Penstemon kunthii and one flower of Penstemon gentryi, close relatives. By the first $4.5 \mathrm{~h}$ of sampling, $87 \%$ of all grains in the anther of the bird-pollinated $P$. kunthii had been released, compared to $21 \%$ of those in the bee-pollinated $P$. gentryi. 